\title{
Therapeutic effects of metformin on insulin resistance and hyperandrogenism in polycystic ovary syndrome
}

\author{
Evanthia Diamanti-Kandarakis, Chryssa Kouli, Thomais Tsianateli and Angeliki Bergiele \\ University of Athens Medical School, First Department of Medicine, Endocrine Section, Laiko Athens General Hospital, Aghiou Thoma 17, Goudi, \\ 11527 Athens, Greece \\ (Correspondence should be addressed to E Diamanti-Kandarakis)
}

\begin{abstract}
Evidence suggests that insulin resistance and hyperinsulinaemia are associated with ovarian hyperandrogenism and menstrual irregularities in polycystic ovary syndrome (PCOS). Sixteen obese women with PCOS on a weight-maintaining diet were studied before and after 6 months of therapy with the insulin-sensitizing antidiabetic agent metformin at a dose of $1700 \mathrm{mg}$ per day. Compared with baseline values, glucose utilization was markedly enhanced at 6 months using the two-step euglycaemichyperinsulinaemic clamp to measure changes in insulin sensitivity $(2.56 \pm 0.32 \mathrm{vs} 4.68 \pm 0.49 \mathrm{mg} /$ $\mathrm{kg}$ per $\mathrm{min}, P=0.0001$, when $40 \mathrm{mU}$ insulin $/ \mathrm{m}^{2}$ per $\mathrm{min}$ was infused, and $6.48 \pm 0.58 \mathrm{vs}$ $9.84 \pm 0.72 \mathrm{mg} / \mathrm{kg}$ per min, $P=0.0002$, when $400 \mathrm{mU}$ insulin insulin $/ \mathrm{m}^{2}$ per $\mathrm{min}$ was infused). The improvement in insulin action was accompanied by significant increases in the levels of sex hormone-binding globulin $(24.5 \pm 7.2$ vs $39.8 \pm 16.2 \mathrm{nmol} / \mathrm{l}, P=0.003)$ and decreases in free testosterone $(12.8 \pm 5.8$ vs $9.0 \pm 3.0 \mathrm{pmol} / \mathrm{l}, \quad P=0.03)$ and androstenedione $(12.9 \pm 5.6$ vs $7.3 \pm 1.7 \mathrm{nmol} / \mathrm{l}, P=0.003)$. No significant changes were recorded in body weight. Seven subjects resumed normal menstruation and two cases of spontaneous pregnancy occurred during treatment. Metformin was well tolerated except for one case of flatulence. These results confirm that metformin treatment can lead to improvements in insulin resistance and ovarian hyperandrogenism.
\end{abstract}

European Journal of Endocrinology 138 269-274

\section{Introduction}

Polycystic ovary syndrome (PCOS) is one of the most common endocrine disorders in premenopausal women with a prevalence rate of $5-10 \%(1)$. It is characterized by ovarian hyperandrogenism and chronic anovulation $(1,2)$. Whilst its aetiology remains unknown, the association between insulin resistance, compensatory hyperinsulinaemia and hyperandrogenism has added new insights into the pathogenesis of the syndrome (2$5)$. Some $20 \%$ of obese women with PCOS have an impaired glucose tolerance test or diabetes $(3,6)$.

Insulin sensitivity is impaired in PCOS and this finding holds in the presence and absence of obesity (3, $7-9)$. Evidence from in vivo and in vitro studies suggests that insulin has both direct and indirect actions on androgen levels. Ovaries removed from women with PCOS exhibit enhanced androstendione and testosterone release in response to insulin stimulation (10). Furthermore, it has been shown that acute increments in insulin levels in women with PCOS induce rises in androgen levels $(11,12)$ whereas a reduction in serum insulin through the use of diazoxide to supress insulin secretion is reported to significantly reduce serum testosterone (13).
Rather surprisingly treatment of hyperandrogenism with gonadotrophin-releasing hormone analogues and certain androgen receptor-blocking agents such as flutamide have failed to improve insulin sensitivity $(14,15)$. However, a recent study has shown some improvement in insulin resistance following the use of antiandrogens (16).

Therapies aimed at reducing hyperinsulinaemia or insulin resistance in PCOS have resulted in slight amelioration of hyperandrogenism and the metabolic abnormalities of the syndrome. The biguanide, metformin, is a drug used routinely for its antidiabetic effects in non-insulin-dependent diabetes mellitus (17). Metformin is claimed to have a multifactorial action with prime effects on insulin sensitivity in both the liver, where it reduces basal hepatic glucose production, and peripheral tissue, where it increases glucose uptake into muscle in the insulin-stimulated state after meals (18, 19). It is antihyperglycaemic in action and does not cause clinical hypoglycaemia.

In non-diabetics, metformin has been investigated for its action on insulin resistance, and improvements in insulin sensitivity have been reported in first-degree relatives of diabetics (20), subjects with upper body obesity (21) and hyperinsulinaemic hypertensive men 
$(22,23)$. In view of the recent interest in the shortterm therapeutic role of metformin in PCOS (24-26), the aims of the present study were to evaluate the simultaneous effects of metformin on insulin sensitivity and the androgenic profile over a total of 6 months.

\section{Subjects and methods}

\section{Subjects}

Sixteen obese (body mass index $(\mathrm{BMI})>27 \mathrm{~kg} / \mathrm{m}^{2}$ ) women with PCOS were studied. Inclusion in the study was restricted to women between the ages of 18 and 31, in good health, euthyroid and who for the 2 months preceding the study had not taken medication (including oral contraceptives) known to alter gonadal function or carbohydrate metabolism.

To gain entry to the study, body weight had to remain stable for at least 2 months before the study; subjects participating in dietary or exercise programmes for weight reduction were excluded. No woman had a history of fasting hyperglycaemia or glycosuria, and at entry glycated haemoglobin had to fall within the normal range. Hyperprolactinaemia and late-onset 21-hydroxylase deficiency, as demonstrated by a $1 \mathrm{~h}$ adrenocorticotrophin stimulation test (27), were checked for, and patients presenting with values outside the normal range were excluded.

The criteria for PCOS diagnosis were elevation of one or more plasma androgen levels with the presence of either chronic oligomenorrhoea or amenorrhoea. All women with PCOS had polycystic ovaries, as confirmed by ovarian ultrasound, but this was not used as a requirement for entry since the syndrome can be present in women with apparently normal ovaries as visualized by ultrasound (28).

The protocol was approved by the Institutional Review Committee of Laiko General Hospital and written informed consent was obtained from each subject before entry into the study.

\section{Study design}

Subjects meeting the entry criteria at baseline were instructed to take $850 \mathrm{mg}$ metformin tablets (Glucophage; Group Lipha, Lyon, France) twice a day with the two main meals of the day for a period of 6 months. To reduce the risk of gastrointestinal side effects, the dose was built up during the first month to the maintenance dose. Patients were asked to attend the clinic each month for routine monitoring.

At baseline and on completion of 6 months, subjects underwent repeat measurements on test days to include a $75 \mathrm{~g} 2 \mathrm{~h}$ oral glucose tolerance test, a two-step euglycaemic-hyperinsulinaemic clamp test $(7,29)$ and blood sampling for assays of testosterone (free and total), sex hormone-binding globulin (SHBG), androstendione and dehydroepiandrosterone sulphate (DHEAS).
Before the test days, patients were asked to adhere to a $300 \mathrm{~g}$ carbohydrate preparatory diet for a total of 3 consecutive days, and on the evening before the test instructed to fast for $10-12 \mathrm{~h}$. The tests were conducted during the first 10 days after the onset of menstruation or after medroprogesterone-induced bleeding. Medroprogesterone $5 \mathrm{mg}$ was given for 7 days to four women at the beginning and to two at the end of the study. The procedures were undertaken about 15-20 days after the administration of the drug.

\section{Two-step euglycaemic clamp}

The patients were studied in the postabsorptive state after a $10-12 \mathrm{~h}$ overnight fast. An intravenous catheter was inserted retrogradely into a dorsal vein on the left and kept warm at $65^{\circ} \mathrm{C}$ via a heated blanket for intermittent sampling of arterialized venous blood. A second catheter was inserted into an antecubital vein in the contralateral arm for administration of glucose and insulin infusions. After collection of three baseline blood samples over $30 \mathrm{~min}$, a primed continuous infusion of crystalline human insulin was started at a rate of $40 \mathrm{mU} / \mathrm{m}^{2}$ per min via an infusion pump for $90 \mathrm{~min}$ to increase plasma insulin levels to approximately $555 \mathrm{pmol} / \mathrm{l}$, while maintaining plasma glucose at the basal level. Plasma glucose was maintained between 80 and $89 \mathrm{mg} / \mathrm{dl}$ by sampling every $5 \mathrm{~min}$ and clamped at this level by periodically adjusting a variable infusion of 20\% dextrose via an Abbot Lifecare infusion pump.

It has been previously demonstrated that hepatic glucose production is suppressed by $90 \%$ at an insulin concentration of approximately $300 \mathrm{pmol} / \mathrm{l}$ (30). Under these conditions, peripheral glucose utilization $(\mathrm{M})$ is equal to the rate of glucose infusion to maintain euglycaemia. The final $30 \mathrm{~min}$ of the infusion period (between 60 and $90 \mathrm{~min}$ ) was used for determination of peripheral glucose utilization. During that steady state, euglycaemia was obtained and the assumption is made that glucose disposal reflects glucose utilization by the peripheral tissue.

After the first equilibration period, the insulin infusion rate was abruptly raised to $400 \mathrm{mU} / \mathrm{m}^{2}$ per min for a further $90 \mathrm{~min}$ in order to increase insulin levels to approximately $10 \mathrm{nmol} / \mathrm{l}$. Peripheral glucose utilization was measured over the period 150-180 min, when steady-state euglycaemia was achieved. At the higher supraphysiological concentration of insulin, insulin receptor responsiveness is maximally increased (7). We have previously shown that women with PCOS have abnormal glucose utilization at these elevated insulin levels (E Diamanti-Kandarakis, C Kouli, T Tsianateli \& A Bergiele, unpublished observations).

\section{Assays}

Plasma glucose was determined by the glucose oxidase method (Beckman Glucose Analyser, Palo Alto, CA, 
USA). Serum insulin was measured with an RIA kit from Medgenix Diagnostics-Biosource Europe SA (Fleurus, Belgium). Duplicate plasma samples were analysed for total testosterone with the TESTO:CTZ RIA Kit (CIS Bio International, Gil-sur-Yvette, France). $\Delta 4$-Androstenedione, SHBG and DHEAS were measured by DSL Diagnostic Systems Laboratories Inc. (DSL Androstenedione RIA Kit, DSL SHBG IRMA Kit, DSL DHEAS RIA Kit).

\section{Data analysis}

Data are expressed as means \pm S.D. or means \pm S.E.M. in the case of glucose utilization measurements. Statistical evaluation was performed using an SAS program. To evaluate the effects of metformin treatment, values before and after 6 months treatment were compared by Student's paired $t$-test and analysis of covariance to assess the changes in insulin resistance independent of changes in body weight.

\section{Results}

A total of 16 patients were recruited to the study but one patient developed unremitting flatulence to metformin and was withdrawn. Two women became pregnant at the end of the study, so they did not participate in the final procedures. The results are given for the remaining 13 subjects who completed 6 months of treatment.

\section{Clinical characteristics of PCOS}

At presentation all 15 subjects were hirsute and in eight cases there was clinical evidence of acanthosis nigricans as diagnosed by the presence of papillomatous hyperpigmentation on the nape of the neck and/or in the axillae.

After 6 months of metformin treatment, pigmentation of the neck was markedly reduced. During the course of the study two women became pregnant, seven resumed regular menstrual cycles and six remained with irregular cycles.

\section{Metabolic and hormonal profiles}

Baseline and 6 month values on metformin treatment are summarized in Table 1 for BMI, androgens and the $2 \mathrm{~h}$ oral glucose tolerance test.

At recruitment the women with PCOS were obese with a mean BMI of $33.6 \pm 6.0 \mathrm{~kg} / \mathrm{m}^{2}$ and body weight of $90.7 \pm 5.4 \mathrm{~kg}$. At 6 months body weight was $88.4 \pm 5.8 \mathrm{~kg}$ representing a small but nonstatistically significant reduction.

Fasting glucose and $2 \mathrm{~h}$ oral glucose tolerance test levels did not change during the study. Fasting insulin levels and $2 \mathrm{~h}$ oral glucose tolerance test insulin levels were reduced about $10 \%$, but this decrease was not statisticaly significant $(P=0.6)$. At baseline one patient met the criteria for impaired glucose tolerance and a further two patients showed increasing signs of glucose intolerance during the course of the study.

Treatment with metformin led to significant changes in sex hormone levels. Free testosterone fell from $12.8 \pm 5.8$ to $9.0 \pm 3.0 \mathrm{pmol} / \mathrm{l}(30 \%$ reduction; $P=$ $0.03)$ whereas SHBG rose from $24.5 \pm 7.2$ to $39.8 \pm$ $16.2 \mathrm{nmol} / \mathrm{l}(62 \%$ increase; $P=0.003)$. Androstenedione levels fell significantly $(P=0.003)$ in line with the fall in free testosterone. Total testosterone was likewise reduced but the change failed to reach statistical significance $(P=0.07)$. No significant changes were observed for DHEAS.

\section{Changes in insulin sensitivity}

Glucose utilization rates showed highly significant increments in response to metformin at both insulin infusion periods (Fig. 1). During the period of hyperinsulinaemia set at $555 \mathrm{pmol} / \mathrm{l}$ and euglycaemia, the glucose utilization rate increased from $2.56 \pm 0.32$ to $4.68 \pm 0.49 \mathrm{mg} / \mathrm{kg}$ per $\min (P=0.0001)$. When insulin levels were set at $10 \mathrm{nmol} / \mathrm{l}$, the glucose utilization rate increased from $6.48 \pm 0.58$ to $9.84 \pm 0.72 \mathrm{mg} / \mathrm{kg}$ per $\min (P=0.0002)$. Repeated measurements of glucose utilization using the clamp technique showed a coefficient of variation of less than $10 \%$.

Table 1 Metabolic and hormonal parameters at baseline and after 6 months of treatment with metformin. Values are means \pm S.D.

\begin{tabular}{lccc}
\hline Variable & Baseline & $\mathbf{6}$ Months & $\boldsymbol{P}$ value \\
\hline BMl $\left(\mathrm{kg} / \mathrm{m}^{2}\right)$ & $33.6 \pm 6.0$ & $32.6 \pm 6.2$ & Not significant \\
DHEAS $(\mu \mathrm{mol} / \mathrm{l})$ & $3.2 \pm 1.6$ & $3.05 \pm 1.93$ & 0.36 \\
SHBG $(\mathrm{nmol} / \mathrm{l})$ & $24.5 \pm 7.2$ & $39.8 \pm 16.2$ & 0.003 \\
Androstenedione $(\mathrm{nmol} / \mathrm{l})$ & $12.9 \pm 5.6$ & $7.3 \pm 1.7$ & 0.003 \\
Free testosterone $(\mathrm{pmol} / \mathrm{l})$ & $12.8 \pm 5.8$ & $9.0 \pm 3.0$ & 0.03 \\
Total testosterone $(\mathrm{nmol} / \mathrm{l})$ & $3.5 \pm 1.9$ & $2.7 \pm 1.0$ & 0.07 \\
Fasting insulin $(\mathrm{pmol} / \mathrm{l})$ & $125 \pm 20.8$ & $111.12 \pm 41.6$ & 0.6 \\
Insulin 2 $\mathrm{h}$ after OGTT $(\mathrm{pmol} / \mathrm{l})$ & $622.5 \pm 854.2$ & $562.5 \pm 486.5$ & 0.2 \\
Fasting glucose $(\mathrm{mg} / \mathrm{dl})$ & $86 \pm 8$ & $88 \pm 9$ & 0.9 \\
Glucose 2h after OGTT $(\mathrm{mg} / \mathrm{dl})$ & $115 \pm 19$ & $128 \pm 26$ & 0.42 \\
\hline
\end{tabular}

OGTT, oral glucose tolerance test. 


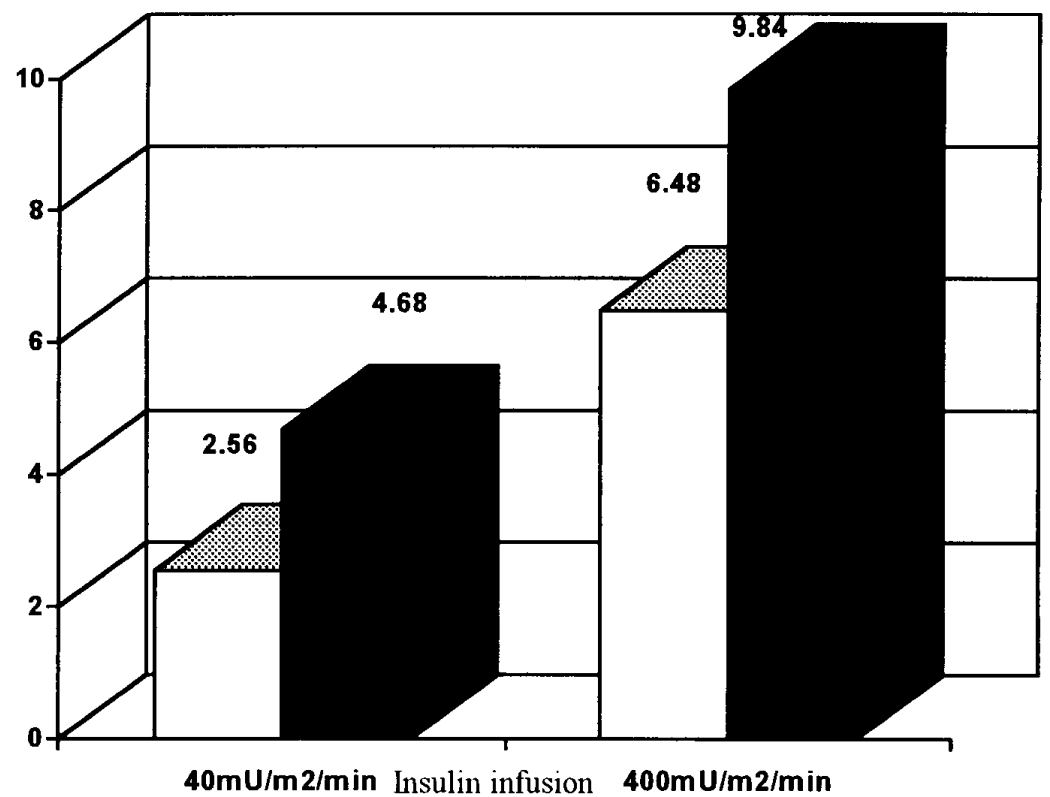

Figure 1 Glucose utilization rates before $(\square)$ and after $(\square) 6$ months of metformin therapy during euglcaemia while the two-step hyperinsulinaemic-euglycaemic clamp was being performed.

The covariance analysis showed that the observed increase in glucose utilization was independent of the changes in body weight $(P<0.0004)$.

\section{Discussion}

Treatment with metformin resulted in significant improvements in insulin sensitivity in women with PCOS. Improved insulin-stimulated glucose utilization was observed at physiological and supraphysiological insulin concentrations, confirming the capacity of metformin to improve insulin action in the presence of normal and elevated insulin concentrations (31). These results are in agreement with the reported findings by Velazquez et al. (24), although they used the insulin response to an oral glucose tolerance challenge as the measure of insulin action. However, they are in contrast with two recently reported studies which have shown no change in insulin sensitivity with metformin treatment $(25,32)$. This disagreement with our study could be due to: (a) the different methods used to assess insulin action (in vivo insulin tolerance test (25) and in vivo glucose tolerance test (32)) which are not as sensitive as the hyperinsulinaemic-euglycaemic clamp (considered to be the gold standard (33)) used in this study; (b) the treatment in both the previous studies lasted less than 3 months; (c) the patients with PCOS studied by Ehrmann et al. (32) were profoundly obese $(\mathrm{BMI}=39 \pm 7.7)$. It has been claimed that the ability of metformin to alter insulin sensitivity in individuals with obesity of this magnitude is limited (32).

The statistically insignificant $(10 \%)$ fall in insulin levels, both at the basal state and after a $75 \mathrm{~g}$ glucose load, supports the view that metformin increases insulin sensitivity rather than secretion (34). The trend for insulin levels to fall in women with PCOS in response to metformin has been confirmed by others $(24,26)$. The non-significant decrease in insulin levels in this study is probably due to the fact that all patients were not markedly hyperinsulinaemic at the beginning.

Recently it has been shown that metformin treatment, through either a direct action or a reduction in insulin levels, is associated with variation in P450c17a enzyme activity, a key enzyme in ovarian androgen synthesis (26).

Improvements in insulin sensitivity were matched by significant reductions in ovarian hyperandrogenism, in particular in the key biological markers of free testosterone and androstendione. These effects appeared to be independent of weight loss, since covariance analysis adjusted for body weight changes showed statistically significant improvement in insulin sensitivity. Since we have intervened therapeutically in PCOS with an insulinsensitizing agent, we assume that the improvement in insulin resistance plays a major role in the decrease in androgen levels. In addition, as shown in the litterature, a fall in androgen levels caused by gonadotrophinreleasing hormone agonists or by antiandrogens results in no or very little improvement in insulin sensitivity (14-16). Our findings support the hypothesis that insulin resistance and hyperinsulinaemia contribute to hyperandrogenism in PCOS $(4,5,10-13)$.

The fall in free testosterone in the absence of any change in total testosterone is consistent with a rise in SHBG and has been reported elsewhere (24). The increase in SHBG is not unexpected given the experimental and 
epidemiological data that exist, supporting the role of insulin in the regulation of hepatic SHBG production. Insulin action, as assessed by the euglycaemic technique, significantly improved during metformin treatment, a finding that could sufficiently explain the rise in SHBG $(35,36)$ Moreover, the observed reduction in androgen levels has contributed to the increase in SHBG.

The observation that DHEAS remained unchanged despite metformin-induced improvements in insulin sensitivity is at variance with some studies $(25,37)$, but is in agreement with others (24). A lack of correlation between changes in DHEAS levels and insulin sensitivity has been noted in a recent study of the insulin-sensitizing agent troglitazone (38). The mechanism underlying these changes is considered to be complex.

The improvement in acanthosis nigricans, although subjective, was significant, as it was reported by the patient and the physician. The degree of improvement was unexpected and no objective criteria were available to assess it. The finding needs further evaluation in a controlled trial. The return to normal menstruation in over $50 \%$ of subjects, and the reporting of two spontaneous pregnancies, has been noted elsewhere and demands further investigation (24).

Our study over a total of 6 months is the longest investigation to date into PCOS and, except for one patient, has confirmed the excellent tolerance of metformin in this group of patients at a daily dose of $1700 \mathrm{mg}$. Metformin is a relatively safe agent provided that the prescribing information is complied with. It does not cause clinical hypoglycaemia through its unique antihyperglycaemic action (17-20). For this reason it has been investigated in various non-diabetic groups with some feature of the insulin-resistance syndrome $(21-23)$.

In conclusion, metformin therapy was effective in reducing insulin resistance and hyperandrogenism in women with PCOS. Although this is not a placebocontrolled study, the findings add further weight to the adverse effects of insulin resistance on the functional status of organ systems. Metformin through its insulinsensitizing action may provide a novel therapy in the management of this common endocrine disorder.

\section{References}

1 Dunaif A, Givens JR, Haseltine FP \& Merriam GR (Eds). The Polycystic Ovary Syndrome. Cambridge, MA: Blackwell Scientific Publications 1992.

2 Polson DW, Wadsworth J, Adams J \& Franks S. Polycystic ovaries: a common finding in normal women. Lancet $19881870-872$.

3 Dunaif A, Segal KR, Futterweit W \& Dobrjansky A. Profound peripheral insulin resistance, independent of obesity, in polycystic ovary syndrome. Diabetes 198938 1165-1174.

4 Diamanti-Kandarakis E \& Dunaif A. New perspectives in polycystic ovary syndrome. Trends in Endocrinology and Metabolism $19967267-271$.

5 Barbieri EL \& Ryan KJ. Hyperandrogenism, insulin resistance and acanthosis nigricans syndrome: a common endocrinopathy with distinct pathophysiologic features. American Journal of Obstetrics and Gynecology 1983147 90-101.

6 Dunaif A, Grat M, Mandeli J, Laumas V \& Dobrjansky A. Characterization of groups of hyperandrogenic women with acanthosis nigricans, impaired glucose tolerance and/or hyperinsulinemia. Journal of Clinical Endocrinology and Metabolism 1987 65 499-507.

7 Dunaif A, Segal KR, Shelley DR, Green G, Dobrjansky A \& Licholai T. Evidence for distinctive and intrinsic defects in insulin action in polycystic ovary syndrome. Diabetes 199241 12571266.

8 Chang RJ, Nakamura RM, Judd HL \& Kaplan SA. Insulin resistance in non obese patients with polycystic ovarian disease. Journal of Clinical Endocrinology and Metabolism 198357 356359.

9 O'Meara NM, Blackman JD, Ehrmann DA, Barnes RB, Jaspan JB, Rosenfield RL \& Polonsky KS. Defects in b-cell function in functional ovarian hyperandrogenism. Journal of Clinical Endocrinology and Metabolism 199376 1241-1247.

10 Barbieri RL, Makris A, Randall RW, Daniels G, Kistner RW \& Rayn KJ. Insulin stimulates androgen accumulation of ovarian stroma obtained from women with hyperandrogenism. Journal of Clinical Endocrinology and Metabolism 198662 904-919.

11 Nestler JE \& Strauss JF III. Insulin as an effector of human ovarian and adrenal steroid metabolism. Endocrinology and Metabolism Clinics of North America 199120 807-819.

12 Scwartz LB \& Diamont MP. The coexistence of hyperandrogenism and hyperinsulinemia (a relationship between reproductive function and carbohydrate metabolism). Infertility and Reproductive Medicine Clinics of North America 19912 611-635.

13 Nestler JE, Barlascini CO \& Matt DW. Suppression of serum insulin by diazoxide reduces serum testosterone levels in obese women with polycystic ovary syndrome. Journal of Clinical Endocrinology and Metabolism 198968 1027-1032.

14 Lasco A, Cucinotta D, Gigaute A, Denuzzo G, Pedulla M, Trifiletti A \& Frisina A. No changes of peripheral insulin resistance in polycystic ovary syndrome after long-term reduction of endogenous androgens with leuprolide. European Journal of Endocrinology $1995133718-722$.

15 Diamanti-Kandarakis E, Mitrakou A, Hennes MMI, Platanissiotis D, Kaklas N, Spina J, Georgiadou E, Hoffmann RG, Kissebah AH \& Raptis S. Insulin sensitivity and antiandrogenic therapy in women with polycystic ovary syndrome. Metabolism 199544 525-531.

16 Moghetti P, Tosi F, Castello R, Magnani CM, Negri C, Brun E, Furlani L, Caputo M \& Muggeo M. Antiandrogens and insulin action. Journal of Clinical Endocrinology and Metabolism 199681 952-960.

17 Bailey CJ \& Turner RC. Metformin drug therapy. New England Journal of Medicine 1996334 574-579.

18 Bailey CJ. Biguanides and NIDDM. Diabetes Care 199215 755772 .

19 Dunn CJ \& Peters DH. Metformin: a review of its pharmacological properties and therapeutic uses in non-insulin dependent diabetes. Drugs $199549721-749$.

20 Widen EIM, Eriksson JG \& Groop LC. Metformin normalizes nonoxidative glucose metabolism in insulin-resistant normoglycemic first-degree relatives of patients with NIDDM. Diabetes 1992 $41354-358$.

21 Scheen AJ, Letiexhe MR \& Lefebvre PJ. Short administration of metformin improves insulin sensitivity in android obese subjects with impaired glucose tolerance. Diabetic Medicine 199512 985989.

22 Dorella M, Giusto M, Tos V, Campagnolo M, Palatini P, Rossi G, Ceolotto G, Felice M, Semplicini A \& Del Prato S. Improvement of insulin sensitivity by metformin treatment does not lower blood pressure of nonobese insulin-resistance hypertensive patients with normal glucose tolerance. Journal of Clinical Endocrinology and Metabolism 199681 1568-1574.

23 Landin K, Tengbom L \& Smith U. Treating insulin resistance in hypertension with metformin reduces both blood pressure and 
metabolic risk factors. Journal of Internal Medicine 1991229181 187.

24 Velazquez EM, Mendoza S, Hamer T, Sosa F \& Glueck CJ. Metformin therapy in polycystic ovary syndrome reduces hyperinsulinemia, insulin resistance, hyperandrogenemia and systolic blood pressure, while facilitating normal menses and pregnancy. Metabolism 199443 647-654.

25 Acbay O \& Gundogdu S. Can metformin reduce insulin resistance in polycystic ovary syndrome? Fertility and Sterility 199665 946-949.

26 Nestler JE \& Jakubowicz DJ. Decreases in ovarian cytochrome p450c17a activity and serum free testosterone after reduction of insulin secretion in polycystic ovary syndrome. New England Journal of Medicine 1996335 617-623.

27 Siegel SF, Finegold DN, Lanes R \& Lee PA. ACTH stimulation tests and plasma dehydroepiandrosterone sulfate levels in women with hirsutism. New England Journal of Medicine 1990323 849-854.

28 Kim MH, Rosentfield RL, Hosseinian AH \& Schneir HG. Ovarian hyperandrogenism with normal and abnormal histologic findings of the ovaries. American Journal of Obstetrics and Gynecology 1979 $134445-452$.

29 De Fronzo RA, Tobin JD \& Andres R. Glucose clamp technique: a method for quantifying insulin secretion and resistance. American Journal of Physiology 1979237 E214-E220.

30 Peiris AN, Aiman EJ, Drucker WD \& Kissebah AH. The relative contribution of hepatic and peripheral tissues to insulin resistance in hyperandrogenic women. Journal of Clinical Endocrinology and Metabolism 198968 715-720.

31 Hother-Nielsen O, Schmitz O, Andersen PH, Beck-Nielsen H \& Pedesen O. Metformin improves peripheral but not hepatic insulin action in obese patients with type ii diabetes. Acta Endocrinologica $1989120257-265$.
32 Ehrmann D, Cavaghan M, Imperial J, Sturis J, Rosenfield R \& Polonsky K. Effects of metformin on insulin secretion, insulin action, and ovarian steroidogenesis in women with polycystic ovary syndrome. Journal of Clinical Endocrinology and Metabolism $199782524-530$.

33 Krentz AJ. Insulin resistance. British Medical Journal 199631 $1385-1389$.

34 Turner R, Cull C \& Holman R. United Kingdom Prospective Diabetes Study 17: a 9-year update of a randomized, controlled trial on the effect of improved metabolic control on complications in non-insulin-dependent diabetes mellitus. Annals of Internal Medicine 1996124 136-145.

35 Peiris AN, Sothmann MS, Aiman EJ \& Kissebah AH. The relationship of insulin to sex hormone-binding globulin: role of obesity. Fertility and Sterility 198952 69-72.

36 Plymate S, Hoop R, Jones R \& Matej L. Regulation of sex hormonebinding globulin production by growth factors. Metabolism 1990 39 967-970.

37 Crave JC, Fimbel S, Lejeune H, Cugnardey N, Dechaud H \& Pugeat M. Effects of diet and metformin administration on sex hormone-binding globulin, androgens and insulin in hirsute and obese women. Journal of Clinical Endocrinology and Metabolism $1995802057-2062$.

38 Dunaif A, Scott D, Finegood D, Quintana B \& Whitcomb R. The insulin-sensitizing agent troglitazone improves metabolic and reproductive abnormalities in the polycystic ovary syndrome. Journal of Clinical Endocrinology and Metabolism 199681 32993306.

Received 24 July 1997

Accepted 6 October 1997 